\title{
E-Textbooks Are Coming: Are We Ready?
}

\author{
Meg Coffin Murray and Jorge Pérez \\ Kennesaw State University, Kennesaw, GA USA \\ mcmurray@kennesaw.edu iperez@kennesaw.edu
}

\begin{abstract}
Textbook options are expanding and the electronic text is poised to become prevalent in the college classroom. Cost pressures are driving this trend even as the academic value of e-textbooks has yet to be established. Limited research is available that examines the effectiveness of the etextbook as a learning tool. This paper presents the results of a study that compares student performance in two sections of an online course, one using an e-textbook and the other using a paper-based text. No significant difference in student performance was found. However, until etextbook format and features are standardized and business models generate sizable cost savings, e-textbook adoption is likely to evolve slowly.
\end{abstract}

Keywords: textbook, e-textbook, e-book, instructional materials.

\section{Introduction}

The textbook is the most widely used instructional material for content dissemination. A traditional textbook is a professionally printed four-color hard-bound book. However, textbook options have expanded via digital content and electronic delivery mechanisms. Many believe that electronic textbooks are poised to become prevalent in the college classroom. Proponents readily cite the advantages of e-textbooks: widespread accessibility, interactivity, increased visual appeal and dynamic linking to supplemental materials. However, for educators, assessing the pedagogical value of e-textbooks is essential. This paper explores the current state of the e-textbook market, examines the issues surrounding adoption of e-textbooks in higher education and compares student performance in two sections of an online course, one using an e-text and another using a paper-based text. The digital age is transforming the textbook market and more and more content is being made available in electronic formats. Further, external pressures are driving a movement toward the adoption of electronic textbooks as a way to cut costs. However, the educational benefit of employing e-textbooks has yet to be established. More research and faculty involvement in assessing these resources is needed.

\section{E-Textbook Market and Demand}

Material published as part of this publication, either on-line or in print, is copyrighted by the Informing Science Institute. Permission to make digital or paper copy of part or all of these works for personal or classroom use is granted without fee provided that the copies are not made or distributed for profit or commercial advantage AND that copies 1) bear this notice in full and 2) give the full citation on the first page. It is permissible to abstract these works so long as credit is given. To copy in all other cases or to republish or to post on a server or to redistribute to lists requires specific permission and payment of a fee. Contact Publisher@InformingScience.org to request redistribution permission.
Electronic textbooks have been on the market for more than a decade. Today, most popular textbook titles are available electronically. However, the adoption of the electronic text in higher education has been slow to materialize. The 2010 Campus Computing Project, which tracks information technology in American higher education, reported that electronic texts were used in $3.5 \%$ of classes with market research reporting that e- 
textbook purchases accounted for only 2\% of textbook sales in 2009 (Kolowich, 2010). While many campuses are experimenting with various e-text options and many college bookstores are offering an e-text alternative, no definitive upward trend in adoption has emerged. Some predict that this is about to change. The latest Simba Information report, E-textbooks in Higher Education (2010) predicts that that the e-text market will grow at a rate of $49 \%$ through 2013 when e-texts will account for $11 \%$ of all textbooks sold. The report attributes the sudden upswing in e-textbook sales to the explosive growth of e-reader devices and e-book apps for smaller computing devices such as tablet PCs and Apple's iPad. The results of the 2010 Campus Computing Survey support this prediction. More than $86 \%$ of the respondents agreed that e-book content and e-book readers will be important components of the instructional resource arena in five years (Campus Computing Project, 2010).

Cost is the primary driver of the e-textbook market. Textbook price increases have been staggering. The average price of a textbook rose 186\% between 1986 and 2005 (Young, 2010) and for the last three years, prices have increased an average of 7.5\% per year (Boroughs, 2010). According to the College Board's 2010 annual survey of the trends in college pricing, the average pubic university student spends US\$1122 a year on course materials. Some campuses have even reported that the cost of textbooks has exceeded the cost of tuition (Young, 2010). In the United States, the issue has become political. The Chairman of the U.S. House of Representatives Committee on Education and Workforce cites that the committee receives more mail about textbook prices than any other issue. While federal legislation has not been written, the committee is investigating ways in which textbooks can be made more affordable, and university faculty and administrators are being encouraged to participate in these endeavors (Powers, 2006).

Electronic texts are generally cheaper to produce than printed texts (Baumann, 2010). The National Association of College Stores (NACS) tracks the breakdown of hard-copy textbook costs. Approximately $22.4 \%$ goes to the bookstore. From this, $18 \%$ is for personnel costs and store operations and $4.4 \%$ is income. Publisher expenditures include $32 \%$ for paper, printing and editorial costs, $15.3 \%$ for marketing, $10 \%$ for administrative costs, $11.6 \%$ for author royalties and $1.7 \%$ for shipping costs. Publisher's income or profit averages approximately $7 \%$. However, the lower printing costs do not necessarily translate into lower e-textbook prices.

There is great disparity in publisher pricing strategies for e-textbooks. In some cases, e-textbooks even cost more than their hardcopy equivalent. Robert Reynolds, President of e-textbook publisher Xplana Learning, Inc., says that publishers are trying to develop profitable business models (Scher, 2006). Publishers cite that costs are shifting rather than being reduced. Major costs in textbook development such as content creation, copy editing and licensing rights remain the same. Additionally, publishers have invested heavily in the development of e-textbook applications and features. Textbook publishers are concerned with protecting their profit margins, and state that static market demand for textbooks makes it difficult to implement aggressive pricing strategies (Scher, 2006). On the other hand, new textbook sales are declining while the used textbook and rental markets, from which textbook publishers reap little revenue, are growing. Etextbook products provide publishers with a way to thwart this competition. Consequently, the etextbook is poised to be a major force in a rapidly evolving textbook market.

Textbook publishers and educators are experimenting with pilot projects using e-textbook offerings. CourseSmart, an e-textbook consortium representing five of the largest textbook publishers, offers more than 9,000 e-textbook titles, which include $90 \%$ of the core textbooks used in higher education (CourseSmart, 2010). CourseSmart offers two options for access, online or an etextbook download. E-textbooks are viewable through proprietary software. Pricing is based on a subscription model with access typically granted for 180 days. CourseSmart reports that it offers e-textbooks for about half of the list price of the hardcopy equivalent. 
Several universities are experimenting with bulk-pricing for high quantities of e-textbook subscriptions, which is seen as another way to potentially drive down prices. For instance, in 2008, the University of Texas at Austin entered into a contract with a publisher to offer an e-textbook option for eight courses that together comprised an enrollment of approximately 1,000 students. The university bought the books under a subscription model, projecting that the bulk purchase would save \$25 to \$45 per book. However, according to Kevin Hegarty, the University VicePresident leading the project, the goal is to achieve a $\$ 20$ to $\$ 25$ price point per book. While free access to the e-textbooks was provided to students during the pilot, the eventual plan would be to add the cost to tuition. Students would no longer buy textbooks. Instead, students would receive access to e-textbooks for courses in which they enroll. The University of California System has also announced a pilot project in which it would purchase bulk quantities of e-textbooks for 32 course sections. The e-textbook will be the only option provided to students enrolled in these sections. This is a model widely adopted by for-profit universities. In fact, the for-profit University of Phoenix requires instructors to assign e-textbooks (Kolowich, 2010).

Other models for the creation, development and delivery of textbooks have also emerged. One such initiative is Flat World Knowledge, whose goal is to provide a "social learning network" that supports broader participation in the creation and dissemination of learning materials. Books are published under a Creative Commons License, allowing instructors the flexibility to adapt a text specifically to meet the needs of an individual course. While the Flat World library is limited, it does offer texts in several disciplines, and the number of offerings continues to grow. In April 2010 , the company reported that its texts were being used in 480 courses by 40,000 students (Boroughs, 2010). What is unique about Flat World is that access to its e-textbooks is free. Moreover, it charges a relatively low price for printed versions and for an e-reader option. For example, a black-and-white paperback-bound textbook costs $\$ 30$, while a color version costs $\$ 60$. Interestingly, Flat World reports that half of its customers choose the free version, and $70 \%$ of paying customers select the black-and-white version.

An open textbook movement is also gaining momentum. An open textbook is made freely available and accessible via the Internet. Users are allowed to not only read the text, but download it and print it at no cost. Several projects such as the Community College Consortium for Open Educational Resources, Google's Collaborative Books Project, Wikibooks, the Global Textbook Project and even Flat World Knowledge are actively pursuing this model. The Student Public Interest Research Groups (Students PIRG), independent activist statewide student organizations, are also actively promoting this work as part of a "Make Textbooks Affordable" campaign. Through their efforts, more than 2,000 professors have signed an agreement stating that they would consider open textbooks when exploring instructional materials.

The e-textbook hype has been building for several years, while the e-textbook has remained on the fringes of full acceptance in higher education. However, several factors are coming together that might propel e-textbooks into a more central role at universities across the globe. Much has been written about the generation of students who expect digital content to be available on various hand-held devices. As experimentation increases and business models evolve, the tipping point in favor of e-textbooks may have finally arrived (Boroughs, 2010).

\section{E-Textbook Format}

The Oxford dictionary defines an e-book to be "an electronic version of a printed book" (Oxford dictionary online, 2010) and the most common e-textbook format is a digitized emulation of their printed counterpart. These e-texts function similarly to the traditional book. For instance, navigation is designed to be linear moving through pages in a sequential manner. In its simplest form, features added to this e-textbook design include bookmarking and searching capabilities. Some also incorporate highlighting of text and note-taking. 
At the other end of the spectrum are e-textbook applications. These designs incorporate mediarich content such as embedded video-clips, sophisticated images and animated graphics. Many also include features such as interactive activities, collaborative note-taking, sharable content highlighting, and group discussion forums. Some textbook publishers have even developed course management software to support their electronic product offerings. Others have features that automatically grade assignments or include 'lecture-capture' software allowing professors to annotate the text using both video and audio recordings. These features are touted as enabling new learning techniques that are not possible with paper-based books (McFall, Dershem, \& Davis, 2006).

The factors driving e-textbook design are more aligned with business models than cognitive science. More research is needed to understand how students interact with an electronic text. Preliminary research has found that students are more likely to skim a computer-based text, often reading in an ' $F$ ' pattern searching for key terms rather than reading line-by-line (Woody, Daniel \&Baker, 2010). They also found that despite hyperlink access to supplemental materials, students were more likely to use special features accompanying printed books than incorporated into etextbooks (Woody, Daniel \& Baker, 2010). It appears that for the current time, students want simple and efficient learning materials and are not willing to pay for additional features (Baumann, 2010). However, the digital transformation is changing the textbook industry. According to Kathy Mickey, analyst and senior editor for Simba, "Students, instructors and publishers are experimenting with the way textbooks and other instructional materials are created, marketed, distributed and used" (Simba, 2010). The monolithic printed textbook is no longer the only option. The real question, however, is how effective are e-textbooks as tools of learning.

\section{Review of Related Research}

A comprehensive research base examining the effectiveness of e-textbooks as instruments of learning does not exist. However, a few studies do appear in the literature. These studies examine e-textbook use in both graduate and under-graduate courses covering a variety of disciplines. Results were mixed in terms of student preference, but impact on student performance was found to be negligible.

McFall, Dershem, and Davis (2006) investigated the incorporation of an e-textbook into an upper level computer science class. Each of the thirteen students participating in the course was given a tablet PC with the e-text preloaded. The e-text was a revised version of a prior edition of a printed text. The e-text was actually incorporated into a larger application that included a set of collaborative tools. These tools allowed students and faculty to create and share annotations, diagrams, notes and bookmarks to internal content pages or to external links. The ability to highlight content for emphasis was also provided. Organization and later retrieval of highlighted sections was facilitated by naming each color used in the highlighting process. An interactive discussion forum was also integrated into the e-textbook application. Student performance in the course and student and instructor perception of the usefulness of the e-text was evaluated.

Student perceptions were generally positive in terms of the usefulness of the e-text. Students particularly rated the collaborative features such as shared annotations as helpful. Students generally reported that the e-text was similar to traditional texts in terms of supporting learning. Student performance was assessed as a measure of time interacting with the text. Students who spent more time 'reading' the text performed better on the final exam. However, it was noted that the student who spent the most time using the text, also received the lowest exam score. The small sample size and the fact that the performance measure was not unique to electronic texts make it difficult to generalize the results of the study. However, the instructor reported overwhelming support for the e-text medium. In fact, he reported that using the e-text had "completely changed the way he taught the class" (McFall, Dershem \& Davis, 2006, p. 343). In particular, he found the 
tools provided in the e-textbook application to be most useful. As those tools are not limited to a particular textbook, the instructor indicated that the next time he taught the course, he would simply use the tools and publicly available content, forgoing use of any textbook.

Woody, Daniel and Baker (2010) examined the preference for e-textbooks of 91 students enrolled in a university level general psychology course. Students reported greater satisfaction using printed books. Additional findings indicated that neither gender nor comfort level with computer technology had an effect on e-textbook preference. Neither did prior e-book use. In fact, all students, regardless of prior experience with e-books, preferred printed texts as tools to support learning. Consequently, the authors concluded that significant hurdles exist to e-textbook adoption. However, study findings showed no difference between student use of electronic texts and paper-based texts in achievement of learning outcomes.

In 2008, Shepperd, Grace, and Koch (2008) evaluated student performance in an introductory psychology class. The students enrolled in the course were given the choice of purchasing a traditional printed text or an electronic version provided on a CD. The electronic text was priced at approximately $\$ 40$ less than the unused printed version. The majority of students, $90 \%$, purchased the paper text. The other $10 \%$, or 37 students, elected the electronic option. Demographic characteristics of the two groups showed no difference in terms of grade point average (GPA), gender, familiarity with computers, location where they studied or their perception of the usefulness of a text in preparing for class. However, those purchasing the electronic text reported more years of college education.

Student performance was assessed on two measures; time spent studying for the class and final course grade. No significant difference was found in the overall course grade between the groups, although the mean grade was slightly higher for those using the paper-text. There was a small, but not significant difference in student reported time spent studying for the class. Students using the electronic text reported spending an average of 2.0 hours per week while students electing the paper-text reported spending an average of 2.3 hours per week. It was unclear what might have attributed to this difference. The authors noted that the amount of time spent studying was unrelated to the grade individual students earned in the course. This held true for both groups of students (Shepperd, Grace, \& Koch, 2008).

Students choosing the e-textbook were asked to assess its usability. Students reported the text to be easy to use but were unfavorable in their ratings of its convenience. The text was distributed on a CD; it was not made available on-line, thereby, limiting its accessibility to computers upon which it was installed. Students were neutral in terms of how they liked the e-text but many indicated they would not recommend it to a friend. Further, only one-third of the students indicated a willingness to use an e-text in the future. The authors surmise that the misgivings students expressed towards the e-textbook could be a factor of novelty and popularity should increase once students become more familiar with reading a text on a computer (Shepperd, Grace, \& Koch, 2008).

Vernon (2006) investigated the use of an online text in a graduate course offered in a Master of Social Work program. The course was offered in the spring semester of 2003. The class, Theories and Methods of Community Practice Interventions, was offered in a traditional on-ground format. The e-text was delivered on-line through the Community Toolbox hosted by the Work Group for Community Health and Development at the University of Kansas. The intent of the study was to identify adaption issues encountered by students when an online text supplants a paper-based text. Students were required to keep a journal providing comments on their use of the online resource. For the first eight weeks of the course, students reported issues using the online text but this subsided about halfway through the course but more than half of the students also reported resorting to making paper copies of the material. Commentary on the online format for delivery of textbook 
content resulted in fifteen positive statements, nine neutral statements and 58 negative statements. Many negative statements focused on physical discomfort such as eyestrain and headaches. Positive comments indicated convenience of accessibility especially in the workplace where reading printed textbooks is often unacceptable. The author concluded that one challenge of e-textbooks is the reliance on technology. Students are still acclimated towards paper but as students' familiarity and comfort with reading online increases, the perceived negative effects of technology as a medium for reading will diminish (Vernon, 2006).

\section{Research Study}

Student performance in two sections of an online IT literacy course was investigated. Students from a variety of majors, including the physical sciences, social sciences, the arts, nursing, business and education, enroll in this course. This course is comprised of three modules: 1) hardware and operating systems, 2) spreadsheet, presentation, and database software, and 3) networks, the Internet, and information literacy. The course was offered in an online asynchronous format. Students were provided with weekly guides that identified learning objectives, assigned readings and required assignments.

One section of the course was assigned a printed text and the other an electronic text. The printed text was customized by the publisher to include only chapters that covered topics included in the course. In addition to the text, the publisher provided supplemental materials such as PowerPoint presentations, publisher produced video clips and a computerized test bank. The e-text was specifically designed to be delivered in an online format. Incorporated within the pages of the e-text were supplemental rich text materials such as short video clips and hyperlinks to additional information. Supplemental PowerPoint presentations and a computerized test bank were also provided with the e-text. Only chapters in the e-text that covered course topics were utilized.

Course assessment included two objective-based exams containing sixty questions. One-third of these questions were specifically constructed to be used in this study. These questions were mapped directly to content covered in the texts. Identical versions of these questions were included on all student exams. Exams were administered on-line and were 'open-book' and 'opennote' meaning students were not restricted from referencing the text while taking the exam. A time limit of 90 minutes to complete an exam was enforced.

Overall average score for the first exam was 86.01 in the section assigned a printed text and 84.31 in the section using the e-textbook. The average score for the twenty questions included on all exams was 85.16 for students with a printed text and 82.07 for students with the e-textbook. While the aggregate difference between the two groups was small, variability was evidenced in responses to individual test questions. However, neither group performed significantly better than the other. In half, or 10 questions, more students using the printed text scored higher while students using the electronic text scored higher in the ten other questions. A similar pattern was evidenced in scores demonstrating the widest gap between correct and incorrect responses. Four questions had a gap greater than $20 \%$ in terms of the number of correct answers. In two of these questions, students using the printed text answered correctly more often. In the other two questions, students using the electronic text answered correctly more often. Figure 1 shows the comparison of correct answers for each question by course section. 


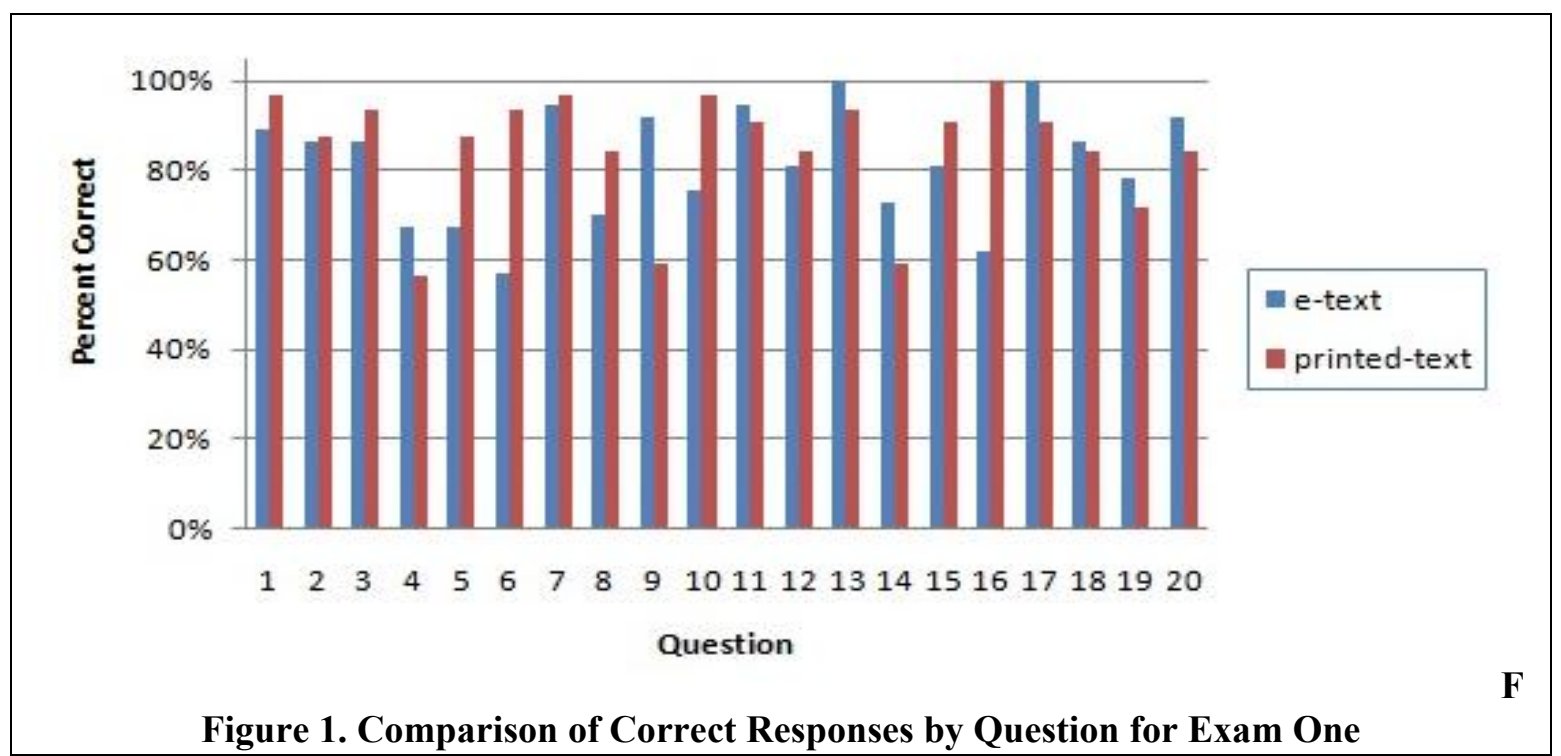

Patterns do emerge when questions were examined in relation to the question topic. Four areas were represented. These included computer concepts, hardware, system software and productivity software. Students using the printed-text scored higher on most questions related to hardware concepts while students using the e-text scored higher on all questions related to productivity software. This may be more reflective of the text coverage of material rather than whether the material was presented in a printed-text or an electronic-text. Table 1 presents the frequency count and percent of correct and incorrect answers for each question for each section of the course categorized by topic for exam one.

Table 1. Comparison of Correct and Incorrect Responses by Topic for Exam One

\begin{tabular}{|c|c|c|c|c|c|c|c|c|}
\hline \multirow[b]{3}{*}{ Question } & \multicolumn{4}{|c|}{ Printed-text } & \multicolumn{4}{|c|}{ Electronic-text } \\
\hline & \multicolumn{2}{|c|}{ Correct } & \multicolumn{2}{|c|}{ Incorrect } & \multicolumn{2}{|c|}{ Correct } & \multicolumn{2}{|c|}{ Incorrect } \\
\hline & $\mathbf{F}$ & $\%$ & $\mathbf{F}$ & $\%$ & $\mathbf{F}$ & $\%$ & $\mathbf{F}$ & $\%$ \\
\hline \multicolumn{9}{|c|}{ Computer Concepts } \\
\hline 1 & 31 & $96.88 \%$ & 1 & $3.13 \%$ & 33 & $89.19 \%$ & 4 & $10.81 \%$ \\
\hline 2 & 28 & $87.50 \%$ & 4 & $12.50 \%$ & 32 & $86.49 \%$ & 5 & $13.51 \%$ \\
\hline 3 & 30 & $93.75 \%$ & 2 & $6.25 \%$ & 32 & $86.49 \%$ & 5 & $13.51 \%$ \\
\hline \multicolumn{9}{|l|}{ Hardware } \\
\hline 4 & 18 & $56.25 \%$ & 14 & $43.75 \%$ & 25 & $67.57 \%$ & 12 & $32.43 \%$ \\
\hline 5 & 28 & $87.50 \%$ & 4 & $12.50 \%$ & 25 & $67.57 \%$ & 12 & $32.43 \%$ \\
\hline 6 & 30 & $93.75 \%$ & 2 & $6.25 \%$ & 21 & $56.76 \%$ & 16 & $43.24 \%$ \\
\hline 7 & 31 & $96.88 \%$ & 1 & $3.13 \%$ & 35 & $94.59 \%$ & 2 & $5.41 \%$ \\
\hline 8 & 27 & $84.38 \%$ & 5 & $15.63 \%$ & 26 & $70.27 \%$ & 11 & $29.73 \%$ \\
\hline 9 & 19 & $59.38 \%$ & 13 & $40.63 \%$ & 34 & $91.89 \%$ & 3 & $8.11 \%$ \\
\hline 10 & 31 & $96.88 \%$ & 1 & $3.13 \%$ & 28 & $75.68 \%$ & 9 & $24.32 \%$ \\
\hline 11 & 29 & $90.63 \%$ & 3 & $9.38 \%$ & 35 & $94.59 \%$ & 2 & $5.41 \%$ \\
\hline \multicolumn{9}{|c|}{ System Software } \\
\hline 12 & 27 & $84.38 \%$ & 5 & $15.63 \%$ & 30 & $81.08 \%$ & 7 & $18.92 \%$ \\
\hline 13 & 30 & $93.75 \%$ & 2 & $6.25 \%$ & 37 & $100.00 \%$ & 0 & $0.00 \%$ \\
\hline 14 & 19 & $59.38 \%$ & 13 & $40.63 \%$ & 27 & $72.97 \%$ & 10 & $27.03 \%$ \\
\hline 15 & 29 & $90.63 \%$ & 3 & $9.38 \%$ & 30 & $81.08 \%$ & 7 & $18.92 \%$ \\
\hline 16 & 32 & $100.00 \%$ & 0 & $0.00 \%$ & 23 & $62.16 \%$ & 14 & $37.84 \%$ \\
\hline
\end{tabular}




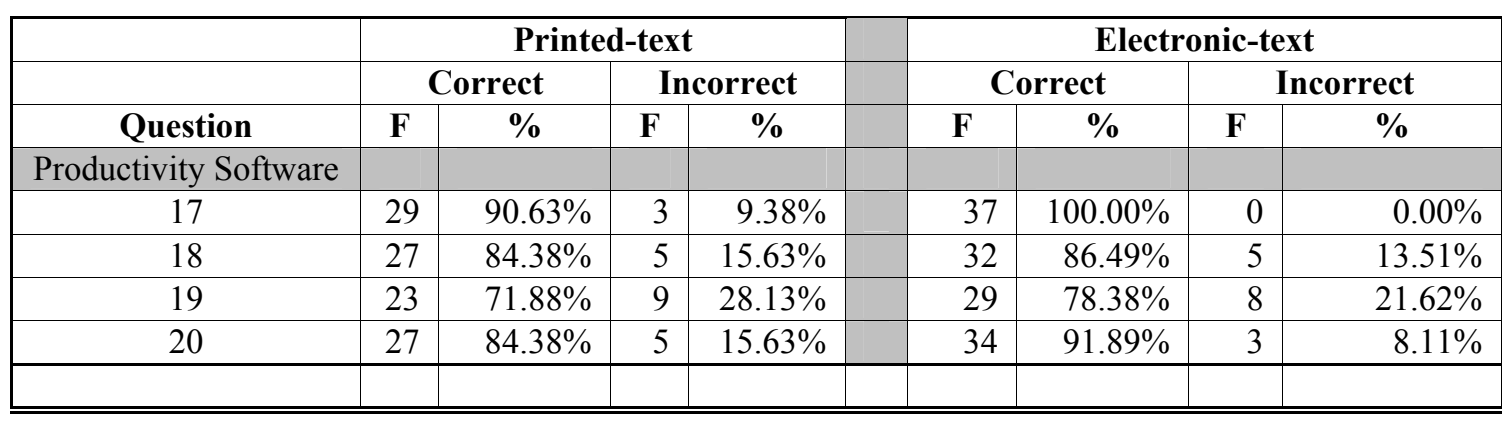

The second exam covered topics related to database technology, network technology and the Internet. Overall scores for this exam were 85.44 for students in the section using the printed text and 86.46 for students using the electronic text. The average score for the twenty questions included on all exams was 92.19 for students with a printed text and 90.10 for students with the etextbook. As in exam one, neither group performed significantly better than the other. In this exam less variability was evidenced in individual test items. Only one question had a gap in the percentage of correct responses that exceeded $20 \%$. On eleven questions more students in the course section using the printed-text gave correct responses. All students answered one question correctly. Students in the section using the electronic text gave more correct responses to eight questions. Figure 2 shows correct responses for each question in exam two by section.

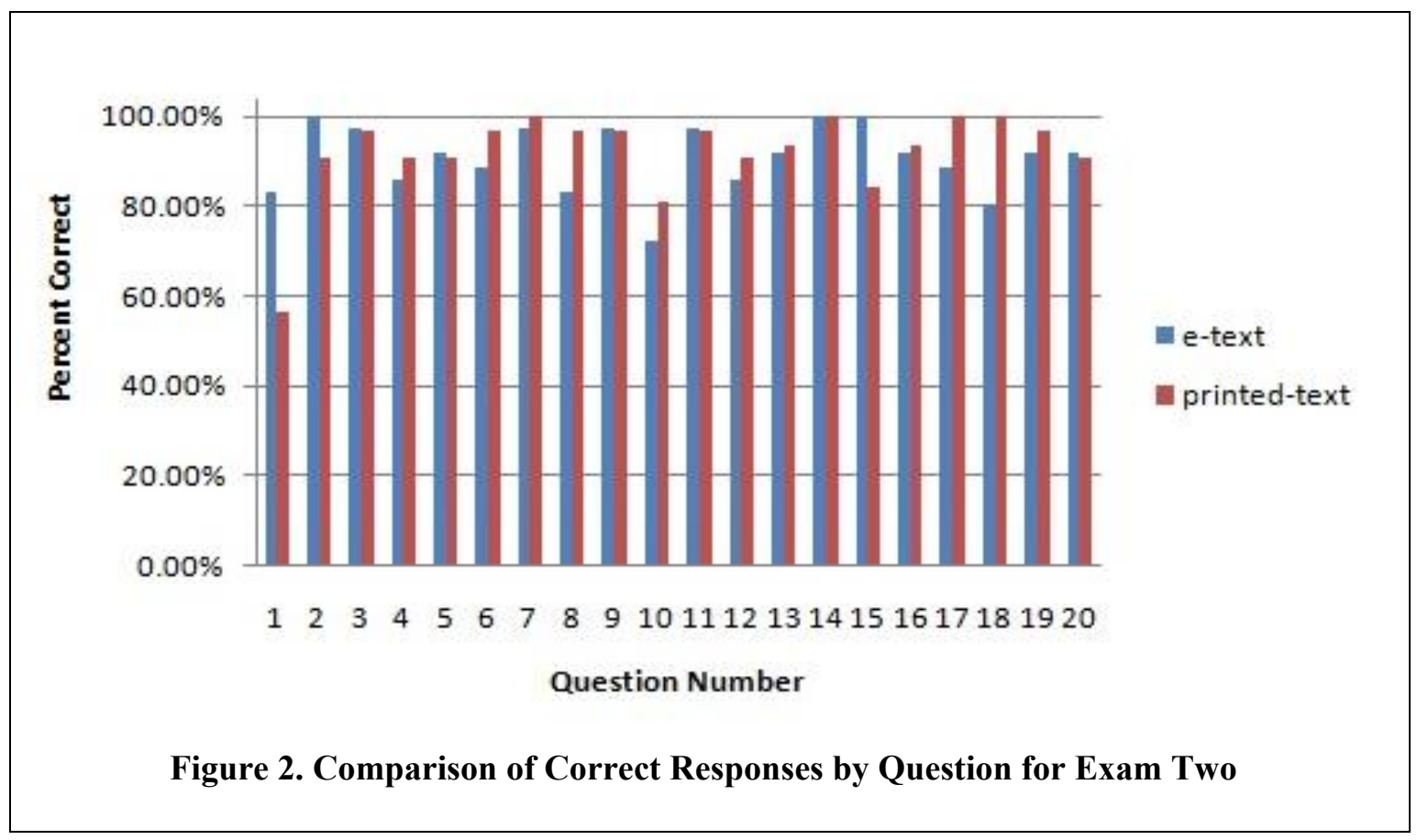

Questions included for review in this exam were related to database technology, Internet interaction, security, Internet searching and network technologies. With the exception of questions related to Internet searching, no other definitive pattern is apparent. Students using the printed-text gave more correct answers for all questions related to Internet searching. In the area of database technologies, students using the electronic text had higher scores in three of the four questions. In the other three areas, the scores were mixed. Table 2 presents the frequency count and percent of 
correct and incorrect answers for each question for each section of the course categorized by topic for exam two.

Table 2. Comparison of Correct and Incorrect Responses by Topic for Exam Two

\begin{tabular}{|c|c|c|c|c|c|c|c|c|}
\hline & \multicolumn{4}{|c|}{ Printed-text } & \multicolumn{4}{|c|}{ Electronic-text } \\
\hline & \multicolumn{2}{|c|}{ Correct } & \multicolumn{2}{|c|}{ Incorrect } & \multicolumn{2}{|c|}{ Correct } & \multicolumn{2}{|c|}{ Incorrect } \\
\hline Question & $\mathbf{F}$ & $\%$ & $\mathbf{F}$ & $\%$ & $\mathbf{F}$ & $\%$ & $\mathbf{F}$ & $\%$ \\
\hline \multicolumn{9}{|c|}{ Database Technology } \\
\hline 1 & 18 & $56.25 \%$ & 14 & $43.75 \%$ & 30 & $83.33 \%$ & 6 & $16.67 \%$ \\
\hline 2 & 29 & $90.63 \%$ & 3 & $9.38 \%$ & 36 & $100.00 \%$ & 0 & $0.00 \%$ \\
\hline 3 & 31 & $96.88 \%$ & 1 & $3.13 \%$ & 35 & $97.22 \%$ & 1 & $2.78 \%$ \\
\hline 4 & 29 & $90.63 \%$ & 3 & $9.38 \%$ & 31 & $86.11 \%$ & 5 & $13.89 \%$ \\
\hline \multicolumn{9}{|c|}{ Internet Interaction } \\
\hline 5 & 29 & $90.63 \%$ & 3 & $9.38 \%$ & 33 & $91.67 \%$ & 3 & $8.33 \%$ \\
\hline 6 & 31 & $96.88 \%$ & 1 & $3.13 \%$ & 32 & $88.89 \%$ & 4 & $11.11 \%$ \\
\hline 7 & 32 & $100.00 \%$ & 0 & $0.00 \%$ & 35 & $97.22 \%$ & 1 & $2.78 \%$ \\
\hline 8 & 31 & $96.88 \%$ & 1 & $3.13 \%$ & 30 & $83.33 \%$ & 6 & $16.67 \%$ \\
\hline 9 & 31 & $96.88 \%$ & 1 & $3.13 \%$ & 35 & $97.22 \%$ & 1 & $2.78 \%$ \\
\hline 10 & 26 & $81.25 \%$ & 6 & $18.75 \%$ & 26 & $72.22 \%$ & 10 & $27.78 \%$ \\
\hline 11 & 31 & $96.88 \%$ & 1 & $3.13 \%$ & 35 & $97.22 \%$ & 1 & $2.78 \%$ \\
\hline 12 & 29 & $90.63 \%$ & 3 & $9.38 \%$ & 31 & $86.11 \%$ & 5 & $13.89 \%$ \\
\hline \multicolumn{9}{|l|}{ Security } \\
\hline 13 & 30 & $93.75 \%$ & 2 & $6.25 \%$ & 33 & $91.67 \%$ & 3 & $8.33 \%$ \\
\hline 14 & 32 & $100.00 \%$ & 0 & $0.00 \%$ & 36 & $100.00 \%$ & 0 & $0.00 \%$ \\
\hline 15 & 27 & $84.38 \%$ & 5 & $15.63 \%$ & 36 & $100.00 \%$ & 0 & $0.00 \%$ \\
\hline \multicolumn{9}{|c|}{ Internet Searching } \\
\hline 16 & 30 & $93.75 \%$ & 2 & $6.25 \%$ & 33 & $91.67 \%$ & 3 & $8.33 \%$ \\
\hline 17 & 32 & $100.00 \%$ & 0 & $0.00 \%$ & 32 & $88.89 \%$ & 4 & $11.11 \%$ \\
\hline 18 & 32 & $100.00 \%$ & 0 & $0.00 \%$ & 29 & $80.56 \%$ & 7 & $19.44 \%$ \\
\hline \multicolumn{9}{|c|}{ Network Technologies } \\
\hline 19 & 31 & $96.88 \%$ & 1 & $3.13 \%$ & 33 & $91.67 \%$ & 3 & $8.33 \%$ \\
\hline 20 & 29 & $90.63 \%$ & 3 & $9.38 \%$ & 33 & $91.67 \%$ & 3 & $8.33 \%$ \\
\hline
\end{tabular}

General assessment of the results of this study indicates no significant difference in student performance between those assigned a printed-textbook and those assigned an electronic textbook. This finding supports previous research. Overall student performance in both sections of this course was similar on both exams as well as on the individual questions selected for review. The high scores could be a result of several factors such as the amount of time given to complete the exams or the fact that the exams were open-book. Student interaction with textbook content does not appear to change regardless of the medium of presentation. 


\section{Conclusion}

The textbook market is changing. No longer is the printed book the only available option. Driven by pressures to reduce textbook costs, experimentation with alternative models, such as the etextbook, is occurring. However, standardization in e-textbook format and features has yet to emerge and pricing-models have yet to generate a sizable enough reduction in cost to make the etextbook a competitive alternative. According to Green of the Campus Computing Project, "eTextbooks do not - yet - provide a compelling value proposition for most college students" (Campus Computing Project, 2010) but he notes that "The platform options, market opportunities, and enabling technologies for eBooks continue to improve."

Price is the top driver of student-buying behavior (Kolowich, 2010). E-textbooks will not catch on until they are the cheapest option and students are not convinced that "e-textbook pricing actually puts money in their pockets" (Boroughs, 2010). According to the Student Public Interest Research Groups, e-textbooks on average cost 39\% more when compared to buying and reselling a paper-based text (Kolowich, 2010). They suggest the price point must represent a savings of more than $50 \%$.

Another school of thought believes that the convergence of digital devices will become a primary driver for e-textbook adoption. As e-textbooks 'escape from the computer' (Scher, 2006), and become readily available on E-readers, smart phones and ipads, their use will become more widespread. The e-reader has been touted as one of the most important developments in the history of books -- as revolutionary as the printing press (Marche, 2009). The electronic reader has the potential to change the way people perceive, define and engage with books (Boroughs, 2010). As delivery options expand, demand for alternative formats for textbooks will also increase.

Research has indicated that student performance is not significantly impacted either by format or delivery mechanism. In fact, the results have been neutral. Expectations for increased student interaction with content promoted by the integration of rich media, hyperlinks to supplemental materials or features that support in-text annotation and note sharing have not materialized. However, these new formats have not been widely utilized and research has yet to uncover how students might more effectively interact with e-textbooks. The value of e-textbooks will increase when they are designed to incorporate digital and interactive features in ways that effectively enhance the teaching/learning process.

Faculty need to learn more about e-textbooks; how they are developed and how they are marketed. Robin Schulze, Head of the English Department at Penn State University stated that "...it's very important for academics in the United Stated to start taking the hardware issues of reading and learning more seriously. We're ceding a lot of important developments to people who are really entertainment engineers" (Musket, Runyon, \& Schulze, 2010 p. 13). E-textbook adoption should be driven by educational value; not by a promise of textbook price reduction. However, according to Baumann (2010), the paradigm shift required to make e-textbooks the norm will make their adoption evolutionary rather than revolutionary. He also contends that "given the choice, faculty and students will flock to the cheapest, most efficient and most readily available option" (Baumann, 2010, p. 48). The future will have a blended model with multiple options. Based on our research, textbook format does not appear to influence student performance in multiple choice tests in IT literacy related subject matter 


\section{References}

Baumann, M. (2010). Ebooks: A new school of thought. Information Today, 27(5).

Boroughs, D. (2010). 'Bye the book: In educational publishing, the only certainty is change. PRISM. Retrieved from http://www.prism-magazine.org/apr10/feature 01.cfm

Campus Computing Project. (2010). The 2010 National Survey of Information Technology in U.S. Higher Education. Retrieved from http://www.campuscomputing.net/2010-campus-computing-survey

College Board. (2010). Trends in college pricing 2010. Retrieved from http://trends.collegeboard.org/college pricing/

CourseSmart. (2010). Company overview. Available from http://www.coursesmart.com/overview

Flat World Knowledge. (2010). Our story: A new approach to college textbooks. Retrieved from http://www.flatworldknowledge.com/

Grensign-Pophal, L. (2010). Are textbooks obsolete: An education in the impact of electronic textbooks. EContent, 22(3), p. 18-23.

Kolowich, S. (2010). All in the delivery. Insider Higher Education. Retrieved from http://www.insidehighered.com/news/2010/08/31/ebooks

Marche, S. (2009). The book that contains all books. Wall Street Journal online. Retrieved from http://online.wsj.com/article/SB10001424052748704322004574475702229446462.html

McFall, R., Dershem, H., \& Davis, D. (2006). Experiences using a collaborative electronic textbook: Bringing the "Guide on the Side" home with you. SIGCSE Bulletin, 3(1), 339-343.

National Association of College Stores. (2010). What's up with textbook pricing? Retrieved from http://www.nacs.org/brochurelicensing/FlatheadValleyCC/WhyTextbooks.pdf

Oxford dictionary online. (2010). Oxford University Press. Retrieved from http://oxforddictionaries.com/view/entry/m en us $1242960 \# \mathrm{~m}$ en us 1242960

Powers, E. (2006). Textbooks, barriers and aid forms. Inside Higher Education. Retrieved from http://www.insidehighered.com/news/2006/09/20/panel

Scher, M. (2006). E-textbook technology catches on slowly. The Eagle. Retrieved from http://www.theeagleonline.com/news/story/e-textbook-technology-catches-on-slowly/

Musket,P., Runyon, D., \& Schulze, R. (2010). E-textbooks: “An interesting ride.” EDUCAUSE Review, 45(2) p. $12-13$

Shepperd, J. A., Grace, J. L., \& Koch, E. J. (2008). Evaluating the electronic textbook: Is it time to dispense with the paper text? Teaching of Psychology, 35, 2-5.

Simba Information. (2010). E-textbooks in higher education 2010-2011. Rockville, MD: Author.

Students Public Interest Research Groups. (n.d.) Make textbooks affordable. Retrieved from http://www.studentpirgs.org/textbooks

Vernon, R. F. (2006). Paper or pixels? An inquiry into how students adapt to online textbooks. Journal of Social Work Education, 42(2), 417-428.

Woody, W. D., Daniel, D. B., \& Baker, C. A. (2010). E-books or textbooks: Students prefer textbooks. Computers \& Education, 55, 945-948.

Young, J. R. (2009). New e-textbooks do more than inform: They'll even grade you. The Chronicle of Higher Education. Retrieved from http://chronicle.com/article/New-E-Textbooks-Do-MoreThan/48324

Young, J. (2010). To save money, colleges may force a switch to e-textbooks. The Chronicle of Higher Education. Retrieved from http://chronicle.com/article/The-End-of-the-Textbook-as-We/125044/ 


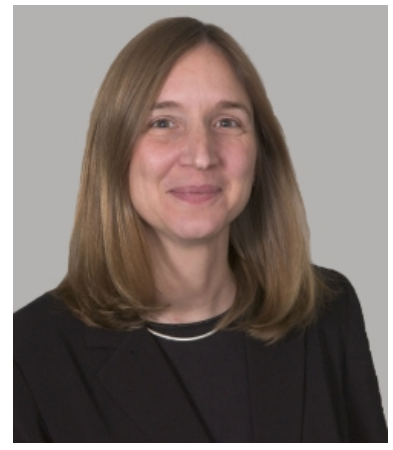

\section{Biographies}

Meg Coffin Murray is a Professor in the Department of Computer Science and Information Systems at Kennesaw State University. She holds a Ph.D. in Information Systems and has over thirty years of experience in both academe and industry. Dr. Murray specializes in the development and implementation of emerging technologies to meet business and societal needs with a special interest in technology infusion in healthcare and in education. Her current work devises strategies to assess and remediate skills needed to leverage IT in innovation, a primary driver of economic growth.

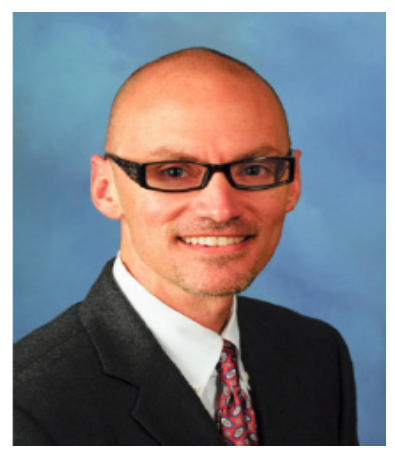

Jorge Pérez is Faculty Executive Assistant to the President and Associate Professor of Information Systems at Kennesaw State University. He holds a Ph.D. in Information Systems from Florida State University, and has two decades of experience in the field as a consultant, systems analyst, web developer, and educator. Professor Pérez has published research on information security, diffusion of innovations, information systems curriculum, and e-learning. His current research on information technology literacy centers on identifying, measuring, and amplifying competencies needed by computer and Internet users. 